\title{
How Much do the Environmental Conditions Interfere with the Essential Oils of Eugenia spp. L. (Myrtaceae)?
}

\author{
Raisa M. Silveira, ${ }^{\circledR *}{ }^{* a}$ Ana F. U. Carvalho, ${ }^{a}$ Mariana O. Bünger, ${ }^{a}$ Manuella M. Gomes ${ }^{a}$ \\ and Itayguara R. da Costa ${ }^{a}$
}

\author{
${ }^{a}$ Departamento de Biologia, Universidade Federal do Ceará, 60355-636 Fortaleza-CE, Brazil
}

\begin{abstract}
Eugenia is the largest neotropical genus in the Myrtaceae family. The genus has a wide geographical distribution, occurring from Mexico to Argentina. Eugenia species are rich in essential oils. Essential oils have applications in perfumery, cosmetics, food, pesticides and medicines. Several factors can influence the chemical composition and yield of essential oils, such as extraction technique, season of the year, genetic variations and environmental conditions. The understanding of how much each of these factors interferes in the formation of essential oils can contribute both to the development of more efficient production processes and to the ecological knowledge of the species of the genus. This study aimed to assess the influence of environmental variables on the chemical composition of essential oils from Eugenia species. The method used was to carry out chemometrics analyzes (regression analysis, factor analysis and multivariate analysis of variance) to explain the influence of environmental factors on the chemical composition of essential oils. The estimated regression model was significant ( $p$-value $<0.05$ ). Environmental variables analyzed significantly influenced and account for $11.5 \%$ of the variation observed in the chemical composition of essential oils. Phytochemical pattern of essential oil composition was also significantly different among Eugenia species.
\end{abstract}

Keywords: chemometrics, essential oils, Eugenia, environmental variables

\section{Introduction}

Eugenia is the largest neotropical genus of the Myrtaceae family, comprising over 1000 species. ${ }^{1}$ The genus has a wide geographic distribution, ranging from Mexico to Argentina. In Brazil, it is present in several vegetation formations. ${ }^{2}$ The genus has several species that produce essential oils, which are used in folk medicine to treat of digestive problems, fever, high blood pressure, diabetes and headache. ${ }^{3,4}$

The demand for essential oils is growing in the industry because of their diverse applications and properties. Essential oils also have applications in perfumery, as cosmetics, food, pesticides and medicines. ${ }^{5}$ The world market for essential oils moves around US $\$ 13$ billion per year. ${ }^{6}$ They have antioxidant, antimicrobial, antiparasitic, antiviral, antifungal, analgesic, anxiolytic, antidepressant, calming, food preservative, anticancer, antispasmodic, carmitive, insecticide, repellent, aromatherapy properties and can be used as a fragrance in perfumery. ${ }^{6}$

*e-mail: raisarms@alu.ufc.br

Editor handled this article: Paulo Cezar Vieira
The challenge in the production of essential oils is the variability of factors that can influence the composition and yield of these oils, such as time of day, season, soil type, leaf age, climate, extraction method, geographic location and genetic variations. ${ }^{7-10}$ Thus, understanding how each of these factors interferes in the formation of essential oils can contribute to more efficient production processes, besides to contributing to the ecological knowledge of the species of the genus. ${ }^{11}$

The influence of environmental factors on the chemical composition of essential oils can be better explained through chemometrics studies. Chemometric uses mathematical and statistical methods to obtain information, pattern recognition and quantitative assessments from the analysis of chemical data. ${ }^{12}$

Costa et $a l .{ }^{13}$ studied the influence of seasonality on the chemical composition of essential oils from E. uniflora from the Brazilian Cerrado. To understand the phytochemical variability of the species, the authors used several chemometric analyzes (principal component analysis, cluster analysis and discriminant analysis). With the results, the authors could identify differences in the chemical composition of essential oils from samples 
collected in the dry and rainy season. The samples from the dry period showed higher percentages of spathulenol and caryophyllene oxide while in the samples from the rainy season the main constituent was the seline-1,3,7(11)-trien8-one epoxide.

Also, according to the authors, ${ }^{13}$ these results contribute to the understanding of the antifungal activity of these essential oils. In fact, essential oils have several biological activities attributed to their constituent chemical compounds. Considering that seasonality can influence the chemical composition, the biological activities of these oils can also be altered.

The same reasoning can be used in the opposite sense: species with similar chemical composition may have similar biological activities. This was the result found by Defaveri et al. ${ }^{14}$ studying Eugenia species collected in Brazilian coastal environments. E. arenosa and E. selloi had very similar antioxidant activity, which the authors attributed to their similar chemical composition.

The variability of the chemical composition of essential oils has to be considered, especially in studies that investigate the pharmacological or medicinal potential of essential oils. In the studies carried out by Siebert et al., ${ }^{15}$ with samples of E. brasiliensis, the chemical composition, yield and antibacterial activities of essential oils were different throughout the seasons.

Chemometrics analyzes have been applied to some Eugenia species in a punctual way. The effects of environmental conditions on the essential oil composition of E. brasiliensis, E. uniflora, E. selloi and E. astringens were investigated in independent studies. ${ }^{13-15}$ Therefore, the genus lacks further comprehensive studies, involving different species that are analyzed simultaneously..$^{15}$ Thus, the aim of the present work was to assess the influence of environmental conditions on the chemical composition of essential oils from Eugenia species through chemometrics analysis.

\section{Experimental}

\section{Bibliographic research}

An extensive literature search was carried out on the specialized sites of scientific journals using the terms "Myrtaceae", "Eugenia", "essential oils", and "chemical composition" between February and December 2019. The selected articles were filtered by some parameters: (i) the part of the plant was the leaf; (ii) the type of oil extraction was using the clevenger apparatus; (iii) the method of analysis of the components of essential oils was gas chromatography coupled with mass spectrometry
(GC-MS). These parameters were chosen because they are the most commonly found in literature. ${ }^{16}$

\section{Phytochemical data}

Phytochemical data on the chemical composition of essential oils referring to Eugenia species got in the bibliographic survey are available in Silveira et al. ${ }^{16}$ In the present study, 53 chemical compounds were analyzed referring to 73 Eugenia species, totaling 204 records. Chemical compounds are represented by their series of compounds. Each column of Table S1 (Supplementary Information (SI) section) includes the isomers of each chemical compound. Such data form the matrix of the original variables or original phytochemical data (Table S1 in the SI section).

\section{Extraction of environmental variables}

The geographic location data (latitude and longitude) have been obtained from the analyzed scientific articles. Climatic information was obtained from files available on the WorldClim version 2.1 website. ${ }^{17}$ The environmental variables used were temperature, water vapor pressure, wind speed, solar radiation and precipitation. Using the "point sampling tool" complement of the Q-GIS version 3.16 program, ${ }^{18}$ it was possible to extract the values of environmental variables for specific geographic coordinates of the Eugenia samples collection sites. The environmental variables were organized and can be analyzed in Table S2, SI section.

\section{Geographic distribution}

The Eugenia species distribution map was made using the Q-GIS version 3.16 program. ${ }^{18}$ The geographic coordinates of each of the samples available in the scientific articles have been plotted for the production of the map in Figure S1 (SI section). Eugenia species have been recorded in different parts of the world. In Figure S1, the species with a record of occurrence in Brazil were represented on the map. The shapefiles of the circumscription of Brazil, South America and the biomes of Brazil were included in the program for preparing the map.

\section{Statistical analysis}

Statistical analyzes were performed in order to determine the influence of environmental conditions on the chemical composition of essential oils from Eugenia 
species. The multivariate analyzes performed are described below.

\section{Factorial analysis}

Factorial analysis aims to summarize the information present in the original variables, transforming them into a smaller number of variables, also called factors, losing as little information as possible. ${ }^{19}$ In this study, factor analysis was performed using the phytochemical data matrix of Eugenia species available in the literature. The method used was principal component analysis (PCA). The generated factors were used to construct a new variable: principal compound index (ICP) of essential oils from Eugenia species.

\section{Principal compounds index}

The aggregate index is a value that condenses information from a set of variables into a single variable. ${ }^{19}$ The factors obtained in the factorial analysis were used to construct the principal compound index (ICP).

The mathematical formula ${ }^{20}$ for obtaining the ICP is described in equation 1 below:

$\mathrm{ICPj}=\sum_{\mathrm{i}=1}^{\mathrm{n}} \mathrm{p}_{\mathrm{i}} \mathrm{f}_{\mathrm{ij}}$

where, ICPj: aggregate index of the $\mathrm{j}^{\text {th }}$ observation, $\mathrm{p}_{\mathrm{i}}$ : weight assigned to the $\mathrm{i}^{\text {th }}$ factor, $\mathrm{f}_{\mathrm{ij}}$ : factorial score of the $\mathrm{i}^{\text {th }}$ component for the $\mathrm{j}^{\text {th }}$ observation, $\mathrm{i}=1, \ldots, \mathrm{k}$ (main components), $\mathrm{j}=1, \ldots, \mathrm{n}$ (observations).

The original ICP was standardized in values ranging from 0 to 1 . The formula used to standardize the ICP values is described in equation 2 below.

$\mathrm{ICP}_{\mathrm{p}}=\frac{\mathrm{ICP}_{\mathrm{ji}}-\mathrm{ICP}_{\mathrm{jr}}}{\mathrm{ICP}_{\mathrm{jm}}-\mathrm{ICP}_{\mathrm{jr}}}$

where, $\mathrm{ICP}_{\mathrm{p}}$ : standardized value of indicator $\mathrm{j}$ in the $\mathrm{i}^{\text {th }}$ observation, $\mathrm{ICP}_{\mathrm{ji}}$ : value of indicator $\mathrm{j}$ in the $\mathrm{i}^{\mathrm{th}}$ observation, $\mathrm{ICP}_{\mathrm{jr}}$ : value of indicator $\mathrm{j}$ in the observation in a lower situation, $\mathrm{ICP}_{\mathrm{jm}}$ : value of indicator $\mathrm{j}$ in the observation in greater situation.

The standardized ICP was used as the dependent variable in the following multiple regression analysis.

\section{Multiple regression analysis}

Dependency statistical technique used to analyze the relationship between a dependent variable and multiple independent variables. ${ }^{19}$ The aim of the analysis is to use the independent variables to predict the values of the dependent variable, as well as to assess the influence that each independent variable has on the dependent variable. ${ }^{19}$
The standardized ICP was used in the regression analysis as the dependent variable and the environmental variables were used as the independent variables. The method selected was 'stepwise regression'. This method makes it possible to select the variables that play an important role in describing the behavior of the dependent variable, and these environmental variables are chosen to compose the database for the regression analysis. With this, it is possible to statistically evaluate the influence that environmental variables have on the standardized ICP and, on the chemical composition of essential oils of Eugenia species.

\section{Multivariate analysis of variance}

Multivariate analysis of variance (MANOVA) is a statistical technique used to, simultaneously, analyze the relationships between multiple categorical independent variables (also called treatments) and two or more quantitative dependent variables. ${ }^{19}$ In this study, the independent variables were Eugenia species. The dependent variables were the environmental and phytochemical variables.

\section{Results}

Phytochemical data were extracted from articles available in the literature. Chemical compounds with a concentration greater than $10 \%$ (main compounds) were considered in the chemometric analyses. Thus, 53 main compounds were analyzed referring to 204 samples and 73 Eugenia species. Due to the large sample size, it was considered that the data had a normal distribution. Environmental data were extracted from maps available on the World Clim website ${ }^{17}$ for temperature, water vapor pressure, precipitation, wind speed and solar radiation. Chemometrics analyzes allowed to assess the influence of environmental variables on the chemical composition of essential oils from Eugenia species. The results of each statistical analysis are described below. Briefly, factor analysis was performed to build the standardized ICP, which was used as an independent variable in the multiple regression analysis. Then, MANOVA was applied to determine the statistical differences between the phytochemical pattern (main compounds of essential oils) and the environmental conditions of the Eugenia species.

\section{Factorial analysis}

Factorial analysis aims to summarize the information present in the original variables. The advantage of this analysis is to transform the original variables into a smaller 
number of variables (also called factors), losing as little information as possible. Factorial analysis reduced the data matrix variables of the chemical composition of essential oils by 24 factors (Table S3, SI section). The factors produced correspond to approximately $70 \%$ of the variation observed in the original variables (Table S4, SI section). The factors were used to construct a new variable: the principal compound index (ICP).

\section{Principal compound index}

The advantage of the aggregated index is that it condenses information from a set of variables into a single variable. In the present study, the factors obtained in the factorial analysis were used to construct the principal compound index. The original ICP was standardized in values ranging from 0 to 1 . The new variable, standardized ICP, corresponds to the variance observed in the original variables of the chemical composition of Eugenia essential oils. Thus, the standardized ICP could be used in the multiple regression analysis representing the chemical composition of Eugenia essential oils.

\section{Regression analysis}

Regression analysis is a dependency statistical technique used to analyze the relationship between a dependent variable and multiple independent variables. The advantage of the analysis is to use the independent variables to predict the values of the dependent variable, as well as to assess the influence that each independent variable has on the dependent variable. In the study, the standardized ICP was used in the regression analysis as a dependent variable and the environmental variables were used as the independent variable. From this analysis, it was possible to create a model to determine the influence of environmental variables on the chemical composition of essential oils.

Multiple regression analysis generated an estimated regression model. The model was significant ( $p$-value $<0.05)$, which means that the environmental variables were able to explain the behavior of the standardized ICP. Consequently, environmental variables influenced the chemical composition of essential oils from Eugenia species (Table 1).

Table 1. Analysis of variance (ANOVA) test of the multiple regression model. The environmental variables of the regression model were precipitation, wind speed, temperature and water vapor pressure

\begin{tabular}{llccccc}
\hline \multicolumn{6}{c}{ ANOVA $^{\mathrm{a}}$} \\
\hline \multirow{2}{*}{ Model } & & $\begin{array}{c}\text { Sum of } \\
\text { squares }\end{array}$ & Df & $\begin{array}{c}\text { Mean } \\
\text { square }\end{array}$ & $F$ & $p$-value \\
\hline \multirow{3}{*}{1} & regression & 0.768 & 5 & 0.154 & 7.564 & $0.000^{\mathrm{b}}$ \\
& residual & 5.034 & 248 & 0.020 & & \\
& total & 5.801 & 253 & & & \\
\hline
\end{tabular}

a Dependent variable: standardized ICP; ${ }^{b}$ predictors: (constant), precipitation, wind speed, temperature, water vapor pressure. Df: degrees of freedom.

The value of $\mathrm{R}^{2}$ (adjusted determination coefficient) indicates how much of the variation in the standardized ICP was explained by the environmental variables $\left(\mathrm{R}^{2}=11.5 \%\right)$. The summary of the model estimated by regression analysis is available in Table 2.

The equation generated by the regression model is expressed below (equation 3):

$\mathrm{ICP}_{\mathrm{p}}=0.534+0.04 \mathrm{VE}+0.19 \mathrm{VA}-0.23 \mathrm{~T}-0.01 \mathrm{P}$

where, $\mathrm{ICP}_{\mathrm{p}}$ : standardized principal compound index value; VE: wind speed; VA: water vapor pressure; T: temperature, $\mathrm{P}$ : precipitation.

The coefficients for each variable were taken from the coefficient values in Table 3 .

\section{Multivariate analysis of variance}

The advantage of MANOVA is to analyze simultaneously the relationships between multiple categorical independent variables (also called treatments) and two or more quantitative dependent variables. In this study, the independent variables were Eugenia species. The dependent variables were the environmental and phytochemical variables. Thus, it was possible to determine that the chemical composition and the environmental conditions of essential oils among Eugenia species were significantly different.

Table 2. Multivariate regression analysis model summary. Model was significant ( $p$-value $<0.05$ ). The value of $\mathrm{R}^{2}$ was equal to $11.5 \%$

\begin{tabular}{|c|c|c|c|c|c|c|c|c|c|}
\hline \multicolumn{10}{|c|}{ Model summary ${ }^{\mathrm{a}}$} \\
\hline \multirow[b]{2}{*}{ Model } & \multirow[b]{2}{*}{$\mathrm{R}$} & \multirow[b]{2}{*}{$\mathrm{R}$ square } & \multirow[b]{2}{*}{$\begin{array}{l}\text { Adjusted } \\
\text { R square }\end{array}$} & \multirow[b]{2}{*}{$\begin{array}{l}\text { Standard error } \\
\text { of the estimate }\end{array}$} & \multicolumn{5}{|c|}{ Change statistics } \\
\hline & & & & & $\begin{array}{l}\text { R square } \\
\text { change }\end{array}$ & $F$ & df1 & $\mathrm{df} 2$ & $p$-value \\
\hline 1 & $0.364^{\mathrm{b}}$ & 0.132 & 0.115 & 0.14247 & 0.132 & 7.564 & 5 & 248 & 0.000 \\
\hline
\end{tabular}

aDependent variable: standardized ICP; ${ }^{b}$ predictors: (constant), precipitation, wind speed, temperature water vapor pressure; R: correlation coefficient; df1: degress of freedom 1; df2: degrees of freedom 2 . 
Table 3. Value of the coefficients of the estimated multiple regression model. From the B coefficients it is possible to construct the multiple regression equation

\begin{tabular}{|c|c|c|c|c|c|c|c|c|}
\hline \multicolumn{9}{|c|}{ Coefficients $^{\mathrm{a}}$} \\
\hline \multirow{2}{*}{ Model } & & \multicolumn{2}{|c|}{ Unstandardized coefficients } & \multirow{2}{*}{$\begin{array}{c}\text { Standardized } \\
\text { coefficients }\end{array}$} & \multirow{2}{*}{$t$} & \multirow{2}{*}{$p$-value } & \multicolumn{2}{|c|}{$95.0 \%$ confidence interval for $\mathrm{B}$} \\
\hline & & B & Standard error & & & & Lower bound & Upper bound \\
\hline \multirow{5}{*}{1} & (constant) & 0.534 & 0.124 & & 4.325 & 0 & 0.291 & 0.777 \\
\hline & wind & 0.04 & 0.015 & 0.185 & 2.584 & 0.01 & 0.009 & 0.07 \\
\hline & water vapor & 0.19 & 0.078 & 0.533 & 2.427 & 0.016 & 0.036 & 0.344 \\
\hline & temperature & -0.023 & 0.009 & -0.456 & -2.605 & 0.01 & -0.041 & -0.006 \\
\hline & precipitation & -0.001 & 0 & -0.21 & -2.383 & 0.018 & -0.001 & 0 \\
\hline
\end{tabular}

${ }^{a}$ Dependent variable: standardized ICP. B: regression equation coefficient; $t: t$ test (individual significance test for each coefficient estimated in regression).

Table 4. Multivariate test summary. The dependent variables were the phytochemical and environmental variables and the independent variables were the different species analyzed. Values of $p$-value $<0.05$ indicate significant differences

\begin{tabular}{|c|c|c|c|c|c|}
\hline \multicolumn{6}{|c|}{ Multivariate tests } \\
\hline$\underline{\text { Effect }}$ & & Value & Hypothesis df & Error df & $p$-value \\
\hline \multirow{3}{*}{ Species $^{\mathrm{a}}$} & Wilks' Lambda & 0.000 & 2209.000 & 1806.122 & 0 \\
\hline & Hotelling's Trace & 26379479693643800000000000000000 & 2209.000 & 1882.000 & 0 \\
\hline & Roy's Largest Root & 23189030534319100000000000000000 & 47.000 & 88.000 & 0 \\
\hline \multirow{4}{*}{ Species $^{b}$} & Pillai's Trace & 4.075 & 235 & 440 & 0 \\
\hline & Wilks' Lambda & 0 & 235 & 423.541 & 0 \\
\hline & Hotelling's Trace & 39.528 & 235 & 412 & 0 \\
\hline & Roy's Largest Root & 19.986 & 47 & 88 & 0 \\
\hline
\end{tabular}

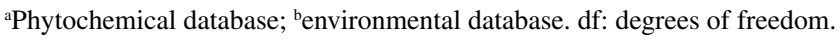

The realization of the multivariate analysis of variance can be analyzed in Table 4 . The results of MANOVA indicates that the environmental conditions and the chemical composition of the essential oils are significantly different between species Eugenia. Visually, the differences in the chemical composition of Eugenia essential oils can be analyzed in Figure S2 (SI section). Graphs containing phytochemical data were constructed for each species analyzed. The graphs described in Figure S2 were drawn from the mean values of the concentrations of the main compounds for each Eugenia species available in Table S1.

\section{Discussion}

The estimated regression model was significant ( $p$-value $<0.05$ ) so changes in the independent variables correlate with shifts in the dependent variable. Thus, it is correct to state that the environmental variables have been able to explain the behavior of the standardized ICP dependent variable. The conception that environmental variables influenced the chemical composition of essential oils was described in previous works and it has been used to explain the chemotypic diversity of Eugenia species. ${ }^{13-15}$
In Figure S1 (SI section), it is possible to observe the samples of Eugenia species occurring in different biomes, which have recognizably distinct environmental conditions. Data on the places of occurrence of Eugenia species were got from the literature. The hypothesis was that species with wide geographic distribution, occurring in different environmental conditions, produced essential oils of chemical composition that were also different from each other. ${ }^{21,22}$ These variants of the same species which differ by the type of essential oil are called chemotypes. The statistical demonstration of this relationship had not been performed until the present work, considering several Eugenia species simultaneously.

Many factors have been mentioned in the literature as capable of influencing the chemical composition of essential oils, such as time of day, season, soil type, age of leaves, climate, extraction method, geographic location and genetic variations. ${ }^{7-10}$ In the present work, the best possible standardization was performed with the data available in the literature. It is important to emphasize that only the essential oils extracted from the leaves were analyzed using the clevenger device extraction method and chemical composition analysis by GC-MS. Another observation to be made is that the works were selected in this way to avoid 
bias in the differences in chemical composition observed among Eugenia species.

Many factors remain without being analyzed and computed, which explains the low value of $\mathrm{R}^{2}$. As many factors influence the chemical composition of essential oils, each factor is then expected to explain a small percentage of the observed variation in the chemical composition of essential oils. With environmental variables, the value of this percentage was $11.5 \%$.

Thus, to better understand the patterns of variation in the chemical composition of essential oils, it is important that further studies are carried out, adding an increasing number of these factors. By adding more information to the regression analysis, the $\mathrm{R}^{2}$ value is expected to increase, improving the predictive power of the estimated regression model.

Another important information provided by the regression analysis is the identification of the environmental variable that most influences the behavior of the dependent variable, with this study, the standardized ICP. The standardized values of the beta coefficient (Table 3 ) show the variables that most contribute to explain the behavior of the dependent variable. ${ }^{19}$ Considering the values observed in Table 3, the water vapor pressure is the most influential variable on the variation of the standardized ICP and regarding the chemical composition of the essential oils of Eugenia species.

One of the biological functions of essential oils in plants is protection against water stress. It is known that the availability of water can influence the chemical composition of essential oils. ${ }^{23}$ In addition, water vapor pressure is related to other variables such as temperature, precipitation, solar radiation and altitude. ${ }^{24,25}$ It is estimated that the higher the altitude, the lower the water vapor pressure.

In turn, higher altitudes are associated with more drastic environmental conditions, which require different levels of environmental tolerance from. ${ }^{26,27}$ Essential oils are also known as volatile oils. ${ }^{6}$ Therefore, volatility is an intrinsic characteristic of essential oils. Depending on their chemical composition, essential oils can be more or less volatile. The vapor pressure of a substance is also related to volatility. The higher the vapor pressure, the more volatile the chemical compound. ${ }^{28}$ Chemical composition, volatility and vapor pressure are closely related. Thus, it is possible to understand the reasons water vapor pressure was the most influential environmental variable on the behavior of the chemical composition of essential oils of Eugenia species, according to the estimated multiple regression model.

\section{Conclusions}

Chemometric analyzes were able to statistically evaluate the influence of environmental conditions on the chemical composition of essential oils from Eugenia species. Through multivariate statistical analysis, it was possible to create a mathematical model to explain the variation in the chemical composition of essential oils according to environmental conditions. Environmental conditions account for $11.5 \%$ of the variation observed in the chemical composition of Eugenia essential oils. The most influential environmental variable on the chemical composition of essential oils was water vapor pressure. The chemical composition of essential oils was significantly different among Eugenia species, as well as the environmental conditions of their respective places of occurrence. It is recommended that further studies be carried out to make the estimated model more robust and increase its predictive power.

\section{Supplementary Information}

Supplementary information (Tables S1 to S4 and Figures S1 and S2) is available free of charge at http://jbcs.sbq.org.br as PDF file.

\section{Acknowledgments}

Acknowledgment to friends and family who collaborated in carrying out this work. Special recognition to IFCE campus Quixadá that granted the license to the server R. M. Silveira.

\section{References}

1. Eugenia; http://www.kew.org/wcsp/, accessed in October 2021.

2. Eugenia; http://floradobrasil.jbrj.gov.br/reflora/floradobrasil/ FB10338, accessed in October 2021.

3. Stefanello, M. E. A.; Pascoal, A. C. R. F.; Salvador, M. J.; Chem. Biodiversity 2011, 8, 73 .

4. Queiroz, J. M.; Suzuki, M. C. M.; Motta, A. P. R.; Nogueira, J. M. R.; Carvalho, E. M.; Rev. Fitos 2015, 9, 73.

5. Bizzo, H. R.; Hovell, A. M. C.; Rezende, C. M.; Quim. Nova 2009, 32, 588.

6. Irshad, M.; Subhani, M.; Ali, S.; Hussain, A. In Biological Importance of Essential Oils, Essential Oils - Oils of Nature; El-Shemy, H. A., ed.; IntechOpen, 2019, DOI: 10.5772/ intechopen.87198.

7. Montanari, R. M.; Barbosa, L. C. A.; Demuner, A. J.; Silva, C. J.; Carvalho, L. S.; Andrade, N. J.; Quim. Nova 2011, 34, 1550. 
8. Serafini, L. A.; Santos, A. C. A.; Touguinha, L. A.; Agostinho, G.; Dalfovo, V.; Extrações e Aplicações de Óleos Essenciais de Plantas Aromáticas e Medicinais; Educs: Caxias do Sul, 2002.

9. Seixas, P. T. L.; Castro, H. G.; Cardoso, P. D.; Júnior, A. F. C.; Nascimento, I. R.; Barbosa, L. C. A.; Bioscience J. 2013, 29, 852.

10. Veloso, R. A.; Castro, H. G.; Barbosa, L. C. A.; Cardoso, D. P.; Chagas Jr., A. F.; Scheidt, G. N.; Rev. Bras. Plant. Med. 2014, 16,364 .

11. Aboukhalid, K.; Al Faiz, C.; Douiak, A.; Bakha, M.; Kursa, K.; Moldoch, M.; Machon, N.; Tomi, F.; Lamiri, A.; Chem. Biodiversity 2017, 14, e1700158.

12. Pereira, P. C. S.; Freitas, C. F. F.; Chaves, C. S.; Estevão, B. M.; Pellosi, D. S.; Hioka, N.; Quim. Nova 2014, 37, 1417.

13. Costa, D. P.; Alves Filho, E. G.; Silva, L. M. A.; Santos, S. C.; Passos, X. S.; Silva, M. R. R.; Seraphin, J. C.; Ferri, P. H.; J. Braz. Chem. Soc. 2010, 21, 851.

14. Defaveri, A. C. A.; Sato, A.; Borré, L. B.; Aguiar, D. L. M.; San Gil, R. A. S.; Arruda, R. C. O.; Riehl, C. A. S.; J. Braz. Chem. Soc. 2011, 22, 1531.

15. Siebert, D. A.; Tenfen, A.; Yamanaka, C. N.; de Cordova, C. M. M.; Scharf, D. R.; Simionatto, E. L.; Alberton, M.; Nat. Prod. Res. 2015, 29, 289.

16. Silveira, R. M.; Carvalho, A. F. U.; Bünger, M. O.; Costa, I. R.; Braz. J. Dev. 2021, 7, 33276.

17. Historical Climate Data; https://www.worldclim.org/data/ worldclim21.html, accessed in October 2021.
18. $Q$-GIS, version 3.16; available at https://qgis.org/en/site/ forusers/download.html, accessed in October 2021.

19. Hair, J. J. F.; Black, W. C.; Babin, B. J.; Anderson, R. E.; Tatham, R. L.; Análise Multivariada de Dados; Artmed Editora: Porto Alegre, 2009.

20. Kubrusly, L. S.; Pesqui. Oper. 2001, 21, 107.

21. Abd-ElGawad, A.; Elshamy, A. I.; El-Amier, Y. A.; El Gendy, A. E.; Al-Barati, S. A.; Assaed, A. M.; Arabian J. Chem. 2020, 13, 4237.

22. Bakha, M.; El Mtili, N.; Machon, N.; Aboukhalid, K.; Amchra, F.; Khiraoui, A.; Gibernau, M.; Tomi, F.; Al Faiz, C.; Arabian J. Chem. 2020, 13, 3070.

23. Sgarbossa, J.; Schmidt, D.; Schwerz, F.; Schwerz, L.; Caron, B. O.; Rev. Ceres 2019, 66, 85.

24. Bernet, L.; Brockmann, E.; Clarmann, T.; Kampfer, N.; Hocke, K.; Atmos. Chem. Phys. 2020, 20, 11223.

25. Nugent, A.; Decou, D.; Russel, S.; Atomosferic Processes and Phenomenon; Open Education Resource: Manoa, 2019.

26. Azócar, A.; Rada, F.; García-Núnez, C.; Interciencia 2007, 32, 663.

27. Silveira, R. M.; Machado, R. M.; Forni-Martins, E. R.; Verola, C. F.; Costa, I. R.; Genet. Mol. Res. 2016, 15, DOI: 10.4238/ gmr15048842.

28. Speight, J. G. In Natural Water Remediation; Speight, J. G., ed.; Butterworth-Heinemann: Oxford, 2020, ch. 2.

Submitted: July 25, 2021 Published online: October 28, 2021 